\title{
Effect of Pavement Thermal Properties on Mitigating Urban Heat Islands: A Multi-scale Modeling Case Study in Phoenix
}

Jiachuan Yang ${ }^{1 *}$, Zhi-Hua Wang ${ }^{1}$, Kamil E. Kaloush ${ }^{1}$, Heather Dylla ${ }^{2}$

${ }^{1}$ School of Sustainable Engineering and the Built Environment, Arizona State University, Tempe, AZ 85287, USA

${ }^{2}$ National Asphalt Pavement Association, Lanham, MD 20706, USA

*Corresponding author. Email: jyang104@asu.edu; Tel: 1-480-727-2917; Fax: 1-480-965-0577 


\section{$1 \quad$ Abstract}

Engineered pavements cover a large fraction of cities and offer significant potential for urban heat island mitigation. Though rapidly increasing research efforts have been devoted to the study of pavement materials, thermal interactions between buildings and the ambient environment are mostly neglected. In this study, numerical models featuring a realistic representation of building-environment thermal interactions, were applied to quantify the effect of pavements on the urban thermal environment at multiple scales. It was found that performance of pavements inside the canyon was largely determined by the canyon geometry. In a highdensity residential area, modifying pavements had insignificant effect on the wall temperature and building energy consumption. At a regional scale, various pavement types were also found to have a limited cooling effect on land surface temperature and 2-m air temperature for metropolitan Phoenix. In the context of global climate change, the effect of pavement was evaluated in terms of the equivalent $\mathrm{CO}_{2}$ emission. Equivalent $\mathrm{CO}_{2}$ emission offset by reflective pavements in urban canyons was only about $13.9-46.6 \%$ of that without building canopies, depending on the canyon geometry. This study revealed the importance of building-environment thermal interactions in determining thermal conditions inside the urban canopy.

Keywords: Building-environment thermal interactions; $\mathrm{CO}_{2}$ emission offset; Energy consumption; Outdoor thermal comfort; Pavement; Urban heat island mitigation 


\section{Introduction}

Urban heat island (UHI), a presence of higher temperatures in an urban area as compared to its rural surroundings, has been considered as one of the major problems in the $21^{\text {st }}$ century [1]. Using satellite-measured surface temperatures, a higher UHI intensity was usually found in summer than that in winter [2]. The adverse effects induced by UHI include but are not limited to, elevated temperatures [3], increased energy consumption [4], air pollution [5], heat-related mortality [6], and disruption to ecosystems [7]. Under the challenge of future climate change, UHI makes cities become unprecedentedly vulnerable to environmental problems that research efforts have been devoted to developing and testing adaptation/mitigation strategies during the past decades [8, 9]. Recognized strategies include reflective roofs [10, 11], green roofs [12, 13], urban vegetation and shading [14-16], heat sinks [17], and cool pavements [18]. Due to the space restrictions in the urban environment, roof material has been extensively studied while pavement material on the ground level has gained limited attention.

Paved surfaces, including roads, parking areas and sidewalks, cover a significant percentage of urban surfaces. A previous study reported that the percentage of paved surfaces ranged from 30 to $39 \%$ as seen from above the urban canopy, and from 36 to $45 \%$ as seen from under the canopy for a variety of metropolitan areas [19]. With such a significant percentage, modification of pavement materials provides a large potential for mitigating urban heat islands. Though a couple of studies have illustrated the capacity of pavements in reducing UHI and building energy consumption, thermal interactions between buildings and the surrounding microclimate in urban canopies are largely neglected [20]. Different from roof materials, pavement are located inside 
41 the urban canyon where buildings substantially alter the heat transport via shading and reflecting

42 radiations. With a three-dimensional building-to-canopy model, Yaghoobian and Kleissl [21]

43 showed that the reflected solar radiation from the reflective pavement can increase annual

44 cooling loads of nearby office buildings by up to $11 \%$ in Phoenix. Li [22] conducted an

45 experimental study in Davis, California and observed that around noon on sunny summer days,

46 the temperature of building walls was $2-5{ }^{\circ} \mathrm{C}$ hotter over concrete pavements than over asphalt

47 pavements. Incorporation of the environmental complexity of built terrains is therefore of critical

48 importance in order to provide useful guidance to energy-efficient designs of buildings and

49 paved surfaces, leading to sustainable city planning. In addition, most existing studies have

50 focused on retrofitting pavements with high albedo or reflective construction materials, thus

51 other pavement materials, such as ones with different thermal capacity and conductivity, have

52 been less studied as strategies for UHI mitigation.

53 Existing studies on the impact of pavements on the urban thermal environment focused on

54 the building-resolving scales and explored offline models where meteorological forcing is

55 provided as boundary conditions [20]. Geographical complexities at city and regional scales,

56 such as spatial heterogeneity, variability in building geometry and density, and local air

57 circulation, are not properly represented. In addition, land-atmosphere interactions are largely

58 neglected in offline models, i.e., meteorological conditions do not respond to changes in building

59 physics. Due to theses limitations, upscaling the results of offline studies for guidance at city and

60 regional scales becomes challenging [23]. Accurate quantification of the effect of pavements on 
61 the urban thermal environment necessarily requires studies in a fully-interacting environment,

62 i.e., a coupled atmosphere-urban modeling system.

In this study, the main objective was to evaluate the effect of pavement thermal properties

64 on the urban thermal environment at multiple scales. Towards this end, numerical models were equivalent $\mathrm{CO}_{2}$ emission offset by reflective pavement due to modified radiative forcing at the

72 global scale was also estimated and discussed.

\section{Numerical Tools and Study Area}

This section describes the numerical tools used to investigate impacts of pavements in the

77 studying the impact at the neighborhood scale. The offline model is suitable for long-term

78 simulations at the neighborhood scale due to its high computational efficiency. However, land-

79 atmosphere interactions are largely neglected in the offline model. At the city and regional

80 scales, an online (coupled) Weather Research and Forecasting (WRF)-Urban modeling system

81 was used to account for the land-atmosphere interactions and surface heterogeneity. 
82 Nevertheless, the requirement of high-performance computational resources imposes constraints on spatial resolution and simulation time of online models.

\subsection{Urban canopy model}

To accurately quantify the impact of pavements in the built environment, a numerical model

87 that captures coupled urban energy and water budgets is needed. Here a state-of-the-art urban canopy model (UCM) [24, 25] was used. The UCM represents building arrays as a twodimensional street canyon, as illustrated in Figure 1(a). The model features a realistic representation of hydrological processes over natural and engineered surfaces, sub-facet heterogeneity, building-environment thermal interaction in the canyon, and analytical solutions to heat transfer in building envelopes. Model performances over various pavement surfaces in the urban area have been validated by in-situ measurements under different climate conditions $[25,26]$. Detailed computational processes of the model can be found in the original paper and thus are not duplicated here.

\section{$97 \quad 2.2$ WRF-Urban modeling system}

During the past decades, a growing concern on urban heat island has led to development of numerous mesoscale atmosphere-urban modeling systems [27-29]. Among the developed systems, one powerful tool is the WRF-Urban modeling system, which has been widely utilized

101 and examined for major metropolitan regions around the world [30-32]. In this study the 102 developed urban canopy model was implemented into the WRF model version 3.4.1 and the new 
103 model was employed to access the impact of pavements at the regional scale. Initial 104 meteorological conditions for the WRF simulations were obtained from the National Centers for 105 Environmental Prediction Final Operational Global Analysis data, which were available on a $1^{\mathrm{o}} \times$ $1061^{\mathrm{o}}$ resolution with a 6-hour temporal frequency (details can be found on 107 http://rda.ucar.edu/datasets/ds083.2/). Land use information was acquired from the National 108 Land Cover Database (NLCD) 2006 [33].

\subsection{Study area}

For the urban canopy model, meteorological measurements in the atmospheric boundary

112 layer are required as model inputs. Observations obtained from the eddy-covariance flux tower 113 deployed at Maryvale, west Phoenix (see Fig. 1(b)) were used to drive offline simulations. The 114 experimental site is a high-density residential area with single-family houses with a mean lot 115 size of about $700 \mathrm{~m}^{2}$ [34]. Generally, the daily mean incoming shortwave radiation is greater than $600 \mathrm{~W} \mathrm{~m}^{-2}$ and the daily mean air temperature at $22 \mathrm{~m}$ is higher than $30{ }^{\circ} \mathrm{C}$ in summer.

117 The monsoon season starts June 29 and ends September 30. The wind speed in the study area is 118 about $3 \mathrm{~m} \mathrm{~s}^{-1}$ in summer, with a prevailing wind direction towards the west [34].

\section{Effect of Canyon Geometry}

121 Urban geometry plays a crucial role in determining the magnitude of shading and trapping 122 effects that its impact on pavement surface temperature needs to be addressed [35]. In this 123 section the sensitivity of pavement surface temperature to canyon geometry was analyzed with 
124 the urban canopy model. Capability of the model in reproducing energy and water budgets of the 125 study residential area at the annual scale (year 2012) was verified in a previous study [36]. The 126 calibrated parameters were summarized in Table 1 and were used for subsequent offline 127 numerical simulations. As reflective pavement has gained increasing popularity recently, it was used as an example to illustrate the effect of canyon geometry. Focusing on the time when the urban thermal environment is extremely aggravated, numerical simulations were carried out for a pre-monsoon summer period, 12-17 June 2012, when high temperatures were observed under clear sky conditions. Pavements were modeled with an albedo (the ratio of reflected radiation 132 from the surface to incident radiation upon it) of $0.1,0.3,0.5$ and 0.7 , while other thermal properties remained the same as shown in Table 1. The first set of simulation modeled a pavement surface without canopy (e.g., open ground space, parking lot), while the second set simulated a pavement surface in the canyon of a typical high-density residential area.

137 shows that increasing pavement albedo significantly reduced surface temperature in the absence 138 of canopy. With an increase of 0.6 in surface albedo, daily peak pavement surface temperature 139 decreased about $23{ }^{\circ} \mathrm{C}$ in average in the simulation period. With the canopy, the reflective 140 material was also able to reduce pavement surface temperature considerably, with a daily peak 141 cooling effect of about $20{ }^{\circ} \mathrm{C}$. However, adjacent buildings blocked part of the incoming solar 142 radiation for the pavement and therefore the albedo was less effective inside the street canyon. 143 Without canopy, temperature difference between pavements with different albedo increased 144 rapidly after sunrise at around 0530 local time. Increasing albedo from 0.1 to 0.7 reduced 
145 pavement surface temperature by more than $10^{\circ} \mathrm{C}$ for about 11 hours. On the other hand, the 146 albedo modification did not cool pavement surface significantly until about 0930 local time with 147 the canopy, when pavement started to become not fully shaded by adjacent buildings. Cooling 148 effect of more than $10{ }^{\circ} \mathrm{C}$ only lasted for about 5 hours, which was less than half of that without 149 canopy. During nighttime, albedo of materials became ineffective due to the absence of solar 150 radiation. However, as more radiation was reflected and less thermal energy was stored during 151 the day, reflective pavement led to a reduction of about $3{ }^{\circ} \mathrm{C}$ in nighttime surface temperature 152 both with and without canopy. It is noteworthy that the nighttime surface temperature of 153 pavement was higher with the canopy due to radiative trapping. Buildings absorbed outgoing 154 longwave radiation from pavement and emitted longwave radiation back. Thermal energy was 155 thus trapped inside the urban canyon that heat storage in the pavement during the day was dissipated slowly.

A third set of simulation was carried out to quantify the effect of canyon aspect ratio $(h / w)$ and canyon orientation $\left(\theta_{c a n}\right)$ on pavement surface temperature. In the simulation the albedo of pavement was increased from 0.1 to 0.7 with varying canyon aspect ratios and orientations, while other parameters remained the same as shown in Table 1. Figure 3(a) presents the averaged diurnal profiles of surface temperature reduction by increasing pavement albedo from 0.1 to 0.7 with different canyon aspect ratios $\left(\theta_{\text {can }}=\pi / 8\right)$. It suggested that cooling effect of reflective pavement decreased with aspect ratio. Daily peak temperature reduction by reflective pavement was about $27{ }^{\circ} \mathrm{C}$ with an aspect ratio of 0.5 , and became around $14{ }^{\circ} \mathrm{C}$ when $h / w$ equaled to 4 . In a deeper street canyon (large $h / w$ value), shading effect of buildings dominates that pavement 
receives incoming solar radiation only around noon time. Under this condition, the effective period of the reflective pavement is significantly reduced. For example, with an aspect ratio of 4, the cooling effect by the reflective pavement was larger than $4{ }^{\circ} \mathrm{C}$ only for the period from 1200 to 1530 local time. The impact of canyon orientations is shown in Fig. 3(b) $(h / w=1)$. Changing the canyon orientation $\theta_{\text {can }}$ modified the pattern of diurnal variation of the cooling effect. For the study area in Phoenix, diurnal profile of the cooling effect with $\theta_{\text {can }}=\pi / 8$ was almost identical to that with $\theta_{\text {can }}=7 \pi / 8$, except that the magnitude was consistently smaller. The efficient period of the reflective pavement (cooling $>5{ }^{\circ} \mathrm{C}$ ) with $\theta_{\text {can }}=5 \pi / 8$ was substantially longer than that with $\theta_{c a n}=\pi / 8$, though the peak cooling effect was close. Among the studied canyon orientations, the maximum daily peak temperature reduction was observed with $\theta_{\text {can }}=3 \pi / 8$, which was about $7^{\circ} \mathrm{C}$ greater than that with $\theta_{c a n}=7 \pi / 8$. Results indicated that when deployed inside a street canyon, the performance of reflective pavements is largely determined by canyon geometry.

\section{Impact of Pavements at a Neighborhood Scale}

\subsection{Surface temperature}

To identify the importance of building-environment thermal interactions in the urban canyon, in this section the effect of pavements on the road and wall surface temperatures in Phoenix was investigated. The sunny pre-monsoon period studied in section 3, 12-17 June 2012, was used for this section. To illustrate the maximum effect of pavements, it was assumed that the road surface was $100 \%$ pavement with no trees or vegetation. For subsequent analysis in this section, an aspect ratio of 1 and a canyon orientation of 0 were used for the study neighborhood. 
Figure 4(a) illustrates that increasing pavement albedo cooled the road surface considerably.

An increase of 0.6 in albedo led to a pavement surface temperature reduction of up to about 20

${ }^{\circ} \mathrm{C}$ in daytime. With reduced road surface temperatures, the reflective pavement emitted less

longwave radiation to the canyon environment. Nevertheless, more shortwave radiation was 
208 were $1.2,2.0$, and $3.0 \mathrm{~W} \mathrm{~K}^{-1} \mathrm{~m}^{-1}$, respectively. Tested heat capacities were $1.4,2.0$, and $2.8 \mathrm{MJ} \mathrm{K}^{-}$ $209{ }^{1} \mathrm{~m}^{-3}$.

210 Results of thermal conductivity are plotted in Fig. 5. Figure 5(a) illustrates that increasing 211 thermal conductivity led to lower road surface temperatures during daytime for Phoenix, as a 212 large thermal conductivity favored the transfer of radiative energy into the pavement. On the 213 other hand, during the nocturnal cycle, heat released from the pavement due to a large thermal 214 conductivity increased the road surface temperature. This indicated that the diurnal variation of 215 road surface temperatures increased with the rate of heat transfer process in the pavement. With an increase of $1.8 \mathrm{~W} \mathrm{~K}^{-1} \mathrm{~m}^{-1}$ in the thermal conductivity, maximum daytime reduction and 217 nighttime increment of the road surface temperature were about 7.0 and $2.4{ }^{\circ} \mathrm{C}$, respectively. In terms of the wall surface temperature, modifying the thermal conductivity of ground pavement had a relatively insignificant impact. Maximum cooling and warming effects were about 1.0 and $1.3{ }^{\circ} \mathrm{C}$, respectively. The effect of heat capacity is shown in Fig. 6, which was similar to the result of thermal conductivity. Enabling ground pavements to store more energy, a large heat capacity tended to reduce the daytime peak road surface temperature. The stored energy was released at night and led to a heating of the road surface. When the heat capacity of ground pavements was doubled 225 from 1.4 to $2.8 \mathrm{MJ} \mathrm{K}^{-1} \mathrm{~m}^{-3}$, maximum daytime reduction and nighttime increment of the road surface temperature were about 5.7 and $2.2{ }^{\circ} \mathrm{C}$ for Phoenix. With respect to the wall surface temperature, modifying the heat capacity of ground pavement led to insignificant cooling and warming effects of up to 1.0 and $0.9{ }^{\circ} \mathrm{C}$. Simulation results in this section illustrated that 
modifying the thermal properties of pavements had a limited impact on the wall surface temperature, even during the hot summer of a year in a desert city.

\subsection{Building energy consumption}

After realizing the effect of different pavement thermal properties on surface temperatures in the urban canyon, a series of simulation was carried out to access the impact of pavement thermal properties on the building energy consumption. Using the calibrated UCM, the effect of pavement thermal properties on the building energy consumption was tested at the annual scale.

To illustrate the effect of same materials on different urban facets, simulations were conducted separately for roof and ground surfaces. Insulation was not considered in this study, which may lead to an overestimation of the building energy consumption. For ground and roof surfaces, four cases were studied. Thermal properties of the material in each case were (1) control case: $a=0.1$, $k=1.2 \mathrm{~W} \mathrm{~K}^{-1} \mathrm{~m}^{-1}, C=1.4 \mathrm{MJ} \mathrm{K}^{-1} \mathrm{~m}^{-3}$; (2) reflective material: $a=0.5, k=1.2 \mathrm{~W} \mathrm{~K}^{-1} \mathrm{~m}^{-1}, C=1.4$ $\mathrm{MJ} \mathrm{K}^{-1} \mathrm{~m}^{-3}$; (3) material of low thermal conductivity: $a=0.1, k=0.6 \mathrm{~W} \mathrm{~K}^{-1} \mathrm{~m}^{-1}, C=1.4 \mathrm{MJ} \mathrm{K}^{-1}$ $\mathrm{m}^{-3}$; and (4) material of large heat capacity: $a=0.1, k=1.2 \mathrm{~W} \mathrm{~K}^{-1} \mathrm{~m}^{-1}, C=2.8 \mathrm{MJ} \mathrm{K}^{-1} \mathrm{~m}^{-3}$. These values were within the typical range of engineering materials documented in the literature. The thickness of materials for roof, wall, and ground were $0.3,0.18$, and $0.45 \mathrm{~m}$, respectively.

Following previous studies [36, 37], the building energy consumption was estimated based on the heat flux entering the building through the innermost layer of the wall and the roof, given by: 


$$
Q_{i n}=\frac{k\left(T_{i n}-T_{B}\right)}{d_{i n} / 2},
$$

where $Q_{i n}$ is the heat flux entering the building via wall or roof, $d_{i n}$ and $T_{i n}$ are the thickness and temperature of the innermost (discrete) layer, $T_{B}$ is the building indoor temperature. With this equation, the estimated energy consumption mainly considers the sensible load of buildings that the latent load is largely ignored. In addition, two factors are neglected: (1) the internal energy loads caused by people and equipment, and (2) the efficiency of air conditioning system and the variation of the building indoor temperature. Note that heat fluxes into the building through roof and wall via conduction were calculated separately in the UCM. As U.S. Department of Energy suggested that the thermostat should be set to around $25.6{ }^{\circ} \mathrm{C}$ for indoor thermal comfort [38], the building indoor temperature was assumed to be maintained at $25{ }^{\circ} \mathrm{C}$ by indoor heating, ventilation, and air-conditioning (HVAC) systems for the entire simulation period.

Figure 7 presents the monthly energy consumption of the building in a residential area in Phoenix. Total annual energy consumptions due to the heat conduction via roof and wall with different materials were summarized in Table 2. Note that in the UCM, the rooftop is not thermally interacted with the street canyon. Therefore Fig. 7(a) represents the effect of various roof materials on the building energy consumption, and Fig. 7(b) illustrates the impact of pavement materials. In terms of the roof surface, Figure 7(a) indicates that the material of low thermal conductivity was the most efficient in reducing building energy consumptions. As it slowed the heat exchange across the building envelope, energy consumptions were substantially reduced throughout the year. Total annual energy consumptions decreased by about $50 \%$ as 
compared to the control case. Increasing albedo and heat capacity of the roof material also led to evident savings of energy consumptions. In cool to cold periods, the reflective material yielded greater energy consumptions than those with a large heat capacity, primarily due to the resulted heating penalty at nighttime. Whereas in summers, warming effects from the material of large heat capacity caused extra cooling demands at night, and the reflective material was more effective in saving building energy consumptions. At the annual scale, increasing the heat capacity of the roof material was more efficient in enhancing the building energy efficiency than increasing albedo for the study area. Compared to deployment of reflective materials, using materials of large heat capacity for the roof surface saved total annual energy consumptions by about $9 \mathrm{kWh} \mathrm{m}^{-2}$. This result emphasizes the previous finding that the thermal performance of materials is determined by multiple parameters, benefits of various mitigation strategies should be compared to come up with the best solution [39].

Figure 7(b) shows that energy consumptions due to the heat conduction via wall was significantly larger than that via roof, mainly due to the difference in the thickness of materials; however, among studied thermal properties, it was found that modifying ground pavements had negligible effects on the building energy consumption. Note that the unit of energy consumptions is $\mathrm{kWh}$ per square meter of wall surface facing the sun. Total annual energy savings in different cases were very small, ranging from -20 to $7 \mathrm{kWh} \mathrm{m}^{-2}$, which was less than $3 \%$ of the annual energy consumption in the control case. Note that the material of low thermal conductivity on roof substantially reduced building energy consumptions, however, it slightly increased the energy consumption of adjacent buildings when deployed at the ground level. The results 
290 illustrate that the same engineering material may lead to an opposite effect on the building energy efficiency when applied to different urban spatial locations.

\subsection{Outdoor thermal comfort}

Under the semi-arid climate, residents experience intense thermal discomfort during hot days in outdoor or non-air-conditioned indoor environments in metropolitan Phoenix [40]. High temperature significantly increases the risk of heat-related morbidity and mortality in cities, especially under the challenge of global warming [41]. Close to pedestrains on the street level, comfort in outdoor urban areas can be a challenging process, due to the variety of environmental factors, including temperature, humidity, wind speed, radiative exposure, ambient evaporative, chosen to assess the impact of pavements on outdoor thermal comfort for Phoenix:

$$
I T S=\left[R_{n}+C+(M-W)\right] / f,
$$

where $R_{n}$ is the body's net radiation, $C$ is the convective energy exchange, $M$ is the heat generated by body's metabolism, $W$ is the heat consumed through work, and $f$ is the efficiency of sweat evaporation. All variables in Equation (2) has the unit of $\mathrm{W} \mathrm{m}^{-2}$ except the dimensionless variable $f$. The ITS is a measure of the rate at which the human body must secrete sweat to maintain thermal equilibrium. It accounts for human metabolism, mechanical work, radiation 
In this study, we assumed a pedestrian was performing mild outdoor activities (e.g.,

312 walking) with light summer clothing in the street canyon. In total four cases were studied for the

313 simulation period of 12-17 June, 2012. Thermal properties of the pavement surface in each case

314 were the same as those listed in Table 2. Increase of the ITS by different pavements as compared

315 to the control case for the entire simulation period is presented in Fig. 8. Figure 8 clearly

316 demonstrates that modifying the thermal conductivity and heat capacity of pavements had

317 negligible impacts on outdoor human thermal comfort across the diurnal cycle. On the other

318 hand, with increased solar reflection, the reflective pavement significantly increased the thermal

319 stress on pedestrians, up to more than $100 \mathrm{~W} \mathrm{~m}^{-2}$ around noontime throughout the simulation

320 period. This finding was in agreement with recent studies where the reduced surface temperature

321 was found not enough to offset increased radiation loads from reflective pavements [44]. In

322 nighttime, the effect of reflective pavements was insignificant as solar radiation was not 323 available.

\section{Regional effect of pavements}

To incorporate the impact of land-atmosphere interaction and land surface heterogeneity, we

327 adopted the coupled WRF-UCM modeling system to quantify the regional effect of pavements

328 for metropolitan Phoenix. Following a previous study's setup [13], we used an inner domain of $329212 \mathrm{~km} \times 212 \mathrm{~km}$ to cover metropolitan Phoenix with a spatial resolution of $2 \mathrm{~km}$. Detailed experimental set-up of the WRF-UCM modeling system is referred to the previous study [13]. 
33211 July, 2006. Using the 2006 NLCD land cover data, the urban land-use was divided into three 333 categories: low-density residential, high-density residential, and industrial and commercial. The 334 performance of the WRF model against field observations from ground-based weather stations 335 for Phoenix has been verified [13]. The calibrated parameters for each land-use category were 336 summarized in Table 3. Thermal properties of pavements in four studied cases were the same as 337 those listed in Table 2 except that the pavement albedo was 0.17 in the control case. Pavement 338 properties were changed for all three urban categories in the simulation. Simulated impact of the 339 reflective pavements on land surface temperature $\left(T_{s}\right)$ and 2-m air temperature $\left(T_{2}\right)$ at 1400 local time is shown in Fig. 9. As shown in Fig. 9, increasing the albedo of pavement surfaces from 0.17 to 0.5 led to a cooling effect of less than $0.5{ }^{\circ} \mathrm{C}$ for Phoenix. This temperature reduction was insignificant given that the surface temperature was higher than $45{ }^{\circ} \mathrm{C}$ at 1400 local time in Phoenix, and was significantly smaller than the predicted reduction from offline simulations. With limited cooling impacts on urban land surface, the reflective pavement had negligible influences on 2-m air temperature. resulted in a lower pavement surface temperature, and the pavement of reduced thermal conductivity led to an elevated surface temperature. The magnitude of temperature change in both cases was less than $0.5{ }^{\circ} \mathrm{C}$, indicating a limited effect of the pavements on land surface temperature. In terms of 2-m air temperature, the effect of both pavements was also negligible 352 (results not shown here). 

magnitude of the temperature change from online simulations was substantially smaller than that predicted by the offline model. The principal reason was that land surface temperature from the WRF-UCM modelling system was a lumped average over all urban surfaces including road, wall, and roof. Existence of bare soil and vegetative surface in urban areas further attenuated the impact of pavements, which could be up to $35 \%$ in low-density residential areas as shown in Table 3. After accounting for the land-atmosphere interaction and land surface heterogeneity, modifying the thermal properties of pavements was found to have a limited effect on urban land surface temperature and air temperature for Phoenix at the regional scale.

\section{6. $\mathrm{CO}_{2}$ emission offset}

At the global scale, the ultimate goal of comparing effects of different pavements is to determine the efficient material for countering global warming. A previous study [45] reported that a net albedo increase of about 0.1 in global urban areas could induce a negative radiative forcing on the earth equivalent to a one-time offsetting $44 \mathrm{Gt}$ of $\mathrm{CO}_{2}$ emissions. $40 \%$ of the emission offset $(20 \mathrm{Gt})$ was achieved by modifying pavement albedo, and the rest $60 \%$ (24 Gt) was accomplished through reflective roofs. Nevertheless, the neglect of thermal interactions inside the urban canyon raises uncertainty for their findings. The UCM used in this study also enables a more realistic estimate of the effect of pavements in terms of $\mathrm{CO}_{2}$ emission offset. As

372 heat capacity and thermal conductivity have no impact on shortwave radiation budgets, only 373 reflective pavements were studied in this section. 

are given by:

$$
\begin{gathered}
S_{W}=\left(1-a_{W}\right)\left(\frac{l_{\text {shadow }}}{2 h}+\frac{w-l_{\text {shadow }}}{w} a_{G} F_{W G}+\frac{l_{\text {shadow }}}{2 h} a_{W} F_{W W}\right) S^{\downarrow}, \\
S_{G}=\left(1-a_{G}\right)\left(\frac{w-l_{\text {shadow }}}{w}+\frac{l_{\text {shadow }}}{2 h} a_{W} F_{W W}\right) S^{\downarrow},
\end{gathered}
$$

where $S$ is the net shortwave radiation and $S^{\downarrow}$ is the download incoming shortwave radiation; subscripts ' $W$ ' and ' $G$ ' denote wall and ground respectively; $l_{\text {shadow }}$ is the normalized shadow length; $F_{W G}$ and $F_{W W}$ are the sky view factors between wall and ground, and between wall and wall, respectively, calculated as:

$$
\begin{gathered}
F_{W W}=\sqrt{1+\left(\frac{w}{h}\right)^{2}}-\frac{w}{h}, \\
F_{W G}=0.5\left(1-F_{W W}\right) .
\end{gathered}
$$

Equations (2) - (5) suggest that the magnitude of outgoing shortwave radiation varies with urban geometry, albedo of ground and wall surfaces, and normalized shadow length. Thus the sensitivity of reflected radiation (from urban canopy to overlying atmosphere) to urban geometry and pavement albedo was investigated for the Phoenix metropolitan area in this section. Other parameters were obtained from Table 1.

Note that the normalized shadow length varies with the solar azimuth angle and zenith angle, therefore the resultant effect of reflective pavements has diurnal and seasonal variations. Following the previous study [45], a 0.15 increase in pavement albedo was assumed for the Phoenix metropolitan area. Diurnal profiles of incoming and reflected shortwave radiations for 
pavements with different canyon aspect ratios are shown in Fig. 11 for the summer solstice day, where a large variability was observed. After sunrise, the albedo of pavement surface began to function by reflecting the reflected shortwave radiation from building walls. As the sun continued to rise, pavements began to receive both direct incoming shortwave radiation from the sun and reflected shortwave radiation from walls. During this period pavement albedo became efficient because direct incoming shortwave radiation was significantly larger than reflected shortwave radiation from walls. Around noontime when the sun was directly overhead, pavements received only direct incoming shortwave radiation from the sun that the impact of pavement albedo inside the urban canopy was similar to that of an open space without canopy in terms of radiative heat exchange. Despite variations of the canyon aspect ratio, a 0.15 increase in

403 pavement albedo increased the reflected shortwave radiation by about $180 \mathrm{~W} \mathrm{~m}^{-2}$ around 404 noontime for all cases. Depending on the canyon aspect ratio, the efficient period of reflective 405 pavement ranged from 3 hours to 7 hours.

To identify the seasonal variation of the impact of reflective pavements on urban shortwave budgets, we employed an index named daily effective albedo. Daily effective albedo is defined as the ratio between total reflected shortwave radiation and total incoming shortwave radiation over an urban canyon across the diurnal cycle. Compared to the material (nominal) albedo, the daily effective albedo is more appropriate for accessing the effect of pavements on urban 411 radiation budgets as it accounts for thermal interaction and geometry effect in cities. Variations 412 of the daily effective albedo for pavements in urban canyons with different aspect ratios is 413 plotted in Figure 12 for year 2012. Figure 12 shows that the daily effective albedo had a larger 
414 seasonal variation in a deeper canyon. Averaging over the entire year 2012, an increase of 0.15 in

415 pavement albedo resulted in an increase of $0.070,0.045$, and 0.021 in the daily effective albedo

416 when $h / w$ equaled to 1,2 , and 4 , respectively. These values were used for calculating the effect

417 of reflective pavements on $\mathrm{CO}_{2}$ emission offset at the global scale.

418 Following the methodology used by Akbari et al. [45], the change in radiative forcing is -

$419 \quad 1.27 \mathrm{~W} \mathrm{~m}^{-2}$ per 0.01 increase in the albedo of global land surface. Considering a global paved

420 surface area of $5.3 \times 10^{11} \mathrm{~m}^{2}$ [45], the increase of $0.021-0.070$ in average daily effective albedo

421 of urban areas is equivalent to an increase of $4.2 \times 10^{-5}-1.4 \times 10^{-4}$ in the Earth's albedo. This

422 corresponds to a radiative forcing change of $5.33-17.78 \mathrm{MW}$ and a one-time global $\mathrm{CO}_{2}$ offset

423 potential of about $2.78-9.33 \mathrm{Gt}$, which is about $13.9-46.6 \%$ of the $20 \mathrm{Gt}$ estimated without

424 considering thermal interactions in the urban canopy. The presented results highlight that the

425 impact of reflective pavements largely depends on the canyon geometry. Moreover, estimating its

426 potential for offsetting greenhouse emission at regional and global scales requires special

427 attention to the heterogeneity of canyon geometry in different cities.

\section{Conclusion}

This study adopted numerical models with building-environment thermal interactions to

431 evaluate the effect of pavement thermal properties on urban environment at multiple scales.

432 Various thermal properties of pavements were tested, including (1) reflectivity, (2) heat capacity, and (3) thermal conductivity. Results showed that the effect of pavement thermal properties on road and wall surface temperatures was largely modulated by the canyon geometry. Due to 
radiative shading effect, modifying thermal properties of pavements had a relatively insignificant impact in the urban canyon as compared to that without canopy. For a high-density residential

437 area in Phoenix, different pavements led to similar wall temperatures and building energy 438 consumptions. When applied to different urban facets, same engineering material may have 439 different effects on the building energy efficiency. In terms of outdoor human thermal comfort, 440 due to increased reflected radiation, reflective pavements increased thermal stress of pedestrians 441 inside the urban canyon considerably, while other pavements did not cause this adverse effect.

442 With dynamic atmospheric modules and detailed land use land cover information, online 443 simulation using the WRF-urban modeling system illustrated that modifying pavements had 444 limited impacts on urban land surface temperature and air temperature for the Phoenix 445 metropolitan area. Considering building-environment thermal interactions, a more realistic 446 impact of reflective pavements in terms of $\mathrm{CO}_{2}$ emission offset and radiative forcing change was 447 estimated. Increase in the daily effective albedo was found to be significantly smaller than the 448 modification of pavement albedo. Depending on the canyon aspect ratio, modifying pavement 449 albedo in the urban canyon led to an offset $13.9-46.6 \%$ of the previous estimate, which did not 450 account for building-environment thermal interactions.

451 Results of numerical simulations suggest that building-environment thermal interactions 452 play a crucial role in determining thermal conditions in urban areas. Accounting thermal 453 interactions in a built environment leads to more realistic and reliable results of numerical 454 simulations. This study provides information regarding how reflective pavements are not an exceptionally effective strategy for mitigating urban heat island and enhancing building energy 
456 efficiency as suggested by previous studies that did not consider building-environment thermal

457 interactions.

458

459 Acknowledgement

460

This work is supported by the National Asphalt Pavement Association and US National

461 Science Foundation under grant number CBET-1435881. 
References

463 [1] Rizwan AM, Dennis LYC, Liu C. A review on the generation, determination and mitigation 464 of Urban Heat Island. Journal of Environmental Sciences. 2008;20(1):120-8.

465 [2] Tran H, Uchihama D, Ochi S, Yasuoka Y. Assessment with satellite data of the urban heat 466 island effects in Asian mega cities. International Journal of Applied Earth Observation and 467 Geoinformation. 2006;8(1):34-48.

468 [3] Wang C, Myint SW, Wang Z, Song J. Spatio-temporal modeling of the urban heat island in 469 the Phoenix metropolitan area: Land use change implications. Remote Sensing. 2016;8(3):185.

470 [4] Akbari H. Cooling our communities. A guidebook on tree planting and light-colored 471 surfacing. Lawrence Berkeley National Laboratory. 2009.

472 [5] Sarrat C, Lemonsu A, Masson V, Guedalia D. Impact of urban heat island on regional 473 atmospheric pollution. Atmospheric Environment. 2006;40(10):1743-58.

474 [6] Tan J, Zheng Y, Tang X, Guo C, Li L, Song G, et al. The urban heat island and its impact on 475 heat waves and human health in Shanghai. International journal of biometeorology. $476 \quad 2010 ; 54(1): 75-84$.

477 [7] Bolund P, Hunhammar S. Ecosystem services in urban areas. Ecological economics. $478 \quad 1999 ; 29(2): 293-301$.

479 [8] Wong E, Akbari H, Bell R, Cole D. Reducing urban heat islands: Compendium of strategies. 480 Environmental Protection Agency, retrieved June 2016.

481 [9] Arnfield AJ. Two decades of urban climate research: a review of turbulence, exchanges of 482 energy and water, and the urban heat island. International journal of climatology. 2003;23(1):1- 
484 [10] Akbari H, Levinson R. Evolution of cool-roof standards in the US. Advances in building energy research. 2008;2(1):1-32.

486 [11] Santamouris M. Cooling the cities-a review of reflective and green roof mitigation 487 technologies to fight heat island and improve comfort in urban environments. Solar Energy. $488 \quad 2014 ; 103: 682-703$.

489 [12] Yang J, Wang Z-H. Physical parameterization and sensitivity of urban hydrological models:

490 Application to green roof systems. Building and Environment. 2014;75:250-63.

491 [13] Yang J, Wang Z-H, Georgescu M, Chen F, Tewari M. Assessing the impact of enhanced 492 hydrological processes on urban hydrometeorology with application to two cities in contrasting 493 climates. Journal of Hydrometeorology. 2016;17(4):1031-47.

494 [14] Akbari H, Pomerantz M, Taha H. Cool surfaces and shade trees to reduce energy use and 495 improve air quality in urban areas. Solar energy. 2001;70(3):295-310.

496 [15] Shashua-Bar L, Hoffman M. Vegetation as a climatic component in the design of an urban 497 street: An empirical model for predicting the cooling effect of urban green areas with trees. 498 Energy and Buildings. 2000;31(3):221-35.

499 [16] Wang Z-H, Zhao X, Yang J, Song J. Cooling and energy saving potentials of shade trees and 500 urban lawns in a desert city. Applied Energy. 2016;161:437-44.

501 [17] Mihalakakou G, Santamouris M, Asimakopoulos D. Use of the ground for heat dissipation. 502 Energy. 1994;19(1):17-25. 
504 review of the actual developments. Renewable and Sustainable Energy Reviews. 2013;26:22450540.

506 [19] Gray KA, Finster ME. The urban heat island, photochemical smog, and Chicago: Local 507 features of the problem and solution: Northwestern University, Department of Civil Engineering, 5081999.

509 [20] Yang J, Wang Z, Kaloush KE. Unintended consequences: A research synthesis examining 510 the use of reflective pavements to mitigate the urban heat island effect. 2013.

511 [21] Yaghoobian N, Kleissl J. Effect of reflective pavements on building energy use. Urban 512 Climate. 2012;2:25-42.

513 [22] Li H. Evaluation of cool pavement strategies for heat island mitigation. [Ph.D. Thesis]. 514 Davis: University of California; 2013. p. 367.

515 [23] Ramamurthy P, Bou-Zeid E, Smith JA, Wang Z, Baeck ML, Saliendra NZ, et al. Influence 516 of Subfacet Heterogeneity and Material Properties on the Urban Surface Energy Budget. Journal 517 of Applied Meteorology and Climatology. 2014;53(9):2114-29.

518 [24] Wang ZH, Bou-Zeid E, Smith JA. A coupled energy transport and hydrological model for 519 urban canopies evaluated using a wireless sensor network. Quarterly Journal of the Royal 520 Meteorological Society. 2013;139(675):1643-57.

521 [25] Wang Z-H, Bou-Zeid E, Smith JA. A spatially-analytical scheme for surface temperatures 522 and conductive heat fluxes in urban canopy models. Boundary-Layer Meteorology. $523 \quad 2011 ; 138(2): 171-93$

524 [26] Song J, Wang Z-H. Impacts of mesic and xeric urban vegetation on outdoor thermal comfort 
525 and microclimate in Phoenix, AZ. Building and Environment. 2015;94:558-68.

526 [27] Best MJ. Representing urban areas within operational numerical weather prediction models.

527 Boundary-Layer Meteorology. 2005;114(1):91-109.

528 [28] Chen F, Kusaka H, Bornstein R, Ching J, Grimmond CSB, Grossman-Clarke S, et al. The 529 integrated WRF/urban modelling system: development, evaluation, and applications to urban 530 environmental problems. International Journal of Climatology. 2011;31(2):273-88.

531 [29] Martilli A, Clappier A, Rotach M. An Urban Surface Exchange Parameterisation for 532 Mesoscale Models. Boundary-Layer Meteorology. 2002;104(2):261-304.

533 [30] Salamanca F, Martilli A, Tewari M, Chen F. A study of the urban boundary layer using 534 different urban parameterizations and high-resolution urban canopy parameters with WRF. 535 Journal of Applied Meteorology and Climatology. 2011;50(5):1107-28.

536 [31] Miao S, Chen F. Formation of horizontal convective rolls in urban areas. Atmospheric 537 Research. 2008;89(3):298-304.

538 [32] Kusaka H, Chen F, Tewari M, Dudhia J, Gill DO, Duda MG, et al. Numerical simulation of 539 Urban Heat Island effect by the WRF Model with 4-km grid increment: an inter-comparison 540 study between the urban canopy model and slab model. Journal of Meteorological Society of $541 \quad J a p a n$ B. 2012;90:33-45

542 [33] Fry JA, Xian G, Jin S, Dewitz JA, Homer CG, LIMIN Y, et al. Completion of the 2006 543 national land cover database for the conterminous United States. Photogrammetric engineering 544 and remote sensing. 2011;77(9):858-64.

545 [34] Ali-Toudert F, Mayer H. Numerical study on the effects of aspect ratio and orientation of an 
546 urban street canyon on outdoor thermal comfort in hot and dry climate. Building and

547 Environment. 2006;41(2):94-108.

548 [35] Song J, Wang Z-H. Interfacing the Urban Land-Atmosphere System Through Coupled

549 Urban Canopy and Atmospheric Models. Boundary-Layer Meteorology. 2014:1-22.

550 [36] Yang J, Wang Z-H. Optimizing urban irrigation schemes for the trade-off between energy

551 and water consumption. Energy and Buildings. 2015;107:335-44.

552 [37] Yang J, Wang Z-H, Chen F, Miao S, Tewari M, Voogt J, et al. Enhancing Hydrologic

553 Modelling in the Coupled Weather Research and Forecasting-Urban Modelling System.

554 Boundary-Layer Meteorology. 2015;155(1):87-109.

555 [38] U.S. Department of Energy. Energy saver: Thermostats. http://energy.gov/energysaver/ 556 thermostats. Retrieved Aug 8, 2016.

557 [39] Yang J, Wang Z-H, Kaloush KE. Environmental impacts of reflective materials: Is high 558 albedo a 'silver bullet'for mitigating urban heat island? Renewable and Sustainable Energy 559 Reviews. 2015;47:830-43.

560 [40] Brazel A, Selover N, Vose R, Heisler G. The tale of two climates-Baltimore and Phoenix 561 urban LTER sites. Climate Research. 2000;15(2):123-35.

562 [41] Patz JA, Campbell-Lendrum D, Holloway T, Foley JA. Impact of regional climate change 563 on human health. Nature. 2005;438(7066):310-7.

564 [42] Mishra AK, Ramgopal M. Field studies on human thermal comfort-An overview. Building 565 and Environment. 2013;64:94-106.

[43] Givoni B. Estimation of the effect of climate on man: Development of a new thermal index: 
567 Technion-IIT, Building Research Station, 1963.

568 [44] Pearlmutter D, Berliner P, Shaviv E. Physical modeling of pedestrian energy exchange 569 within the urban canopy. Building and Environment. 2006;41(6):783-95.

570 [45] Akbari H, Menon S, Rosenfeld A. Global cooling: increasing world-wide urban albedos to 571 offset CO2. Climatic Change. 2009;94(3-4):275-86.

572 
(a)

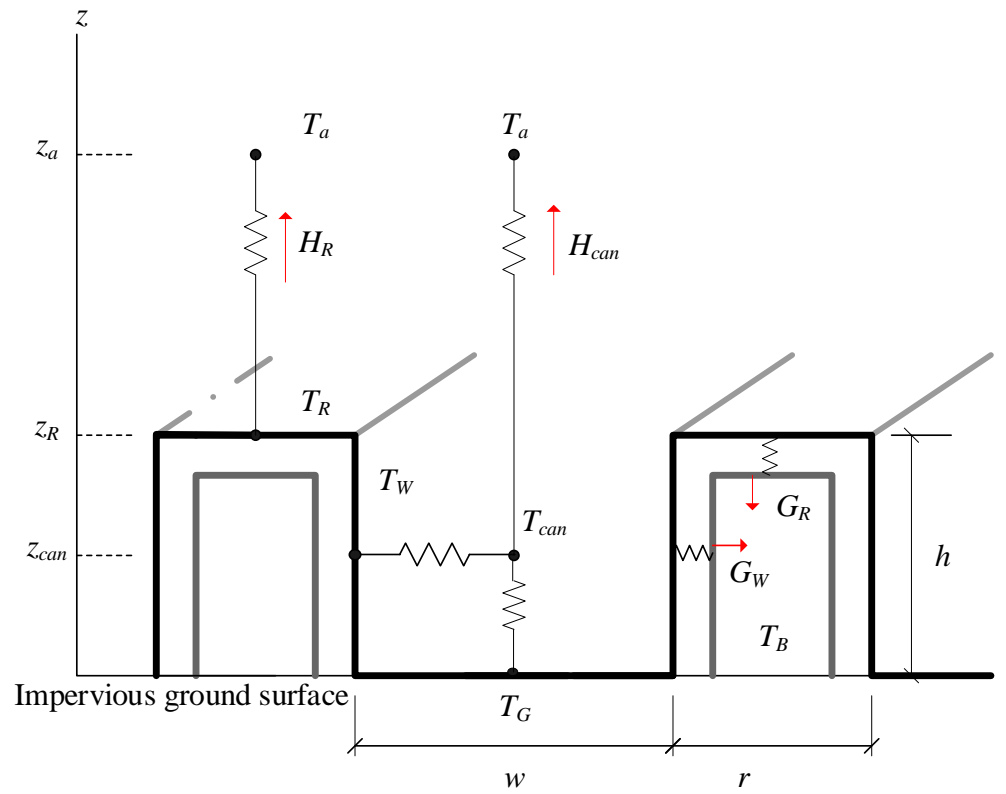

(b)

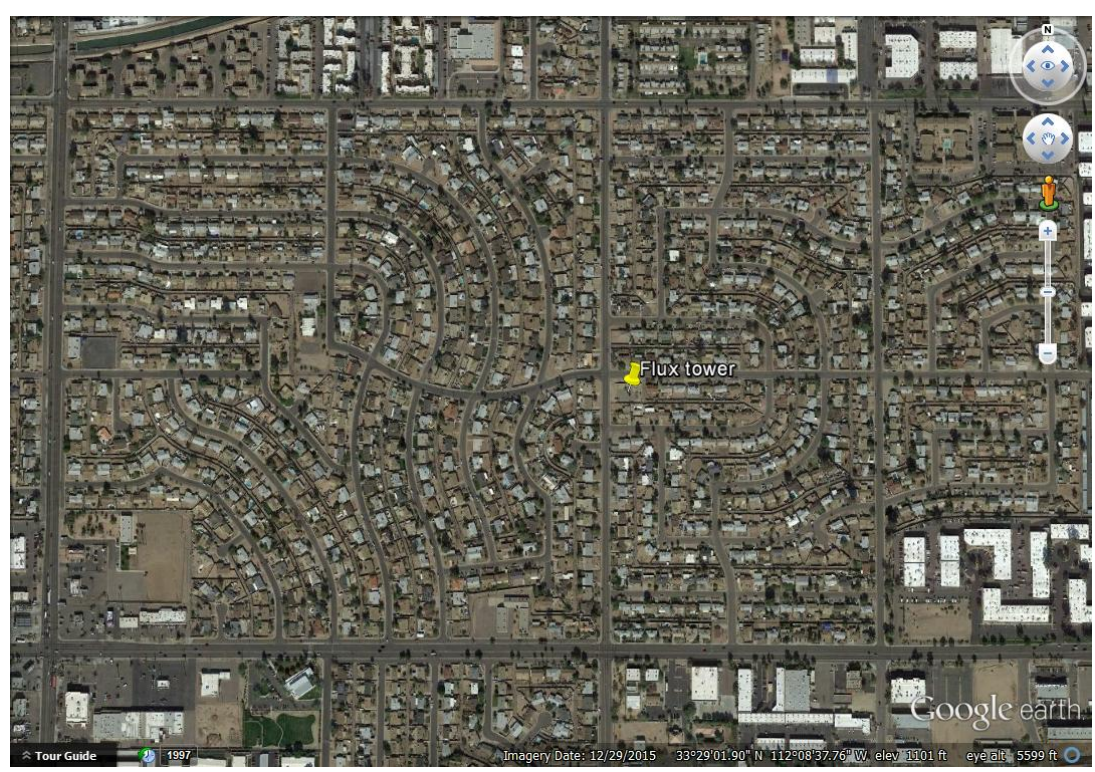

572 Figure 1. (a) Schematic of the urban canopy model: $h, w$, and $r$ are the normalized building

573 height, canyon width, and building width, respectively; $H$ is the sensible heat flux, $G$ is the

574 storage heat flux, $T$ is the temperature, $z$ is the height, subscripts $R, W, G$, can, $a, B$ denote

575 properties of roof, wall, ground, canyon, air and building. (b) Location of the flux tower in a

576 high-density residential area in Phoenix (Google Earth basemap). 
(a)

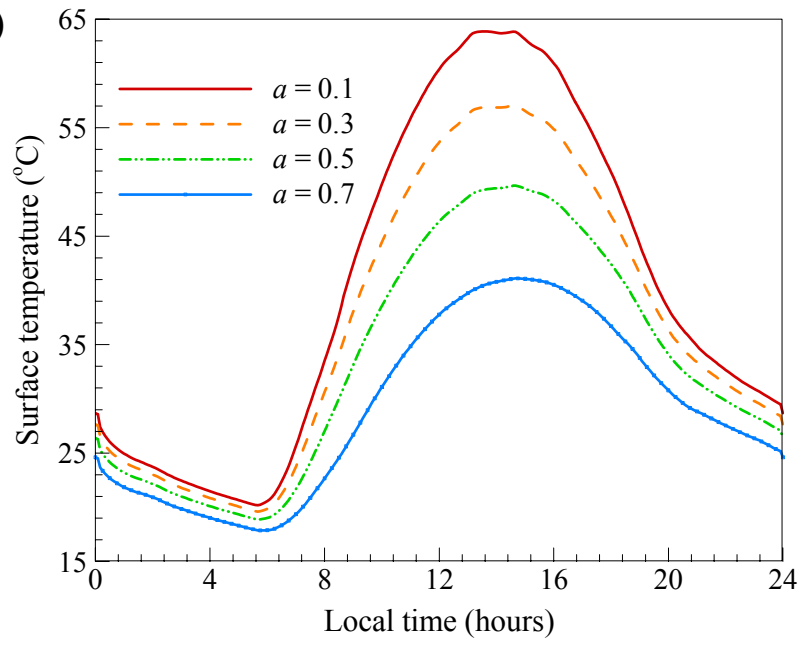

(b)

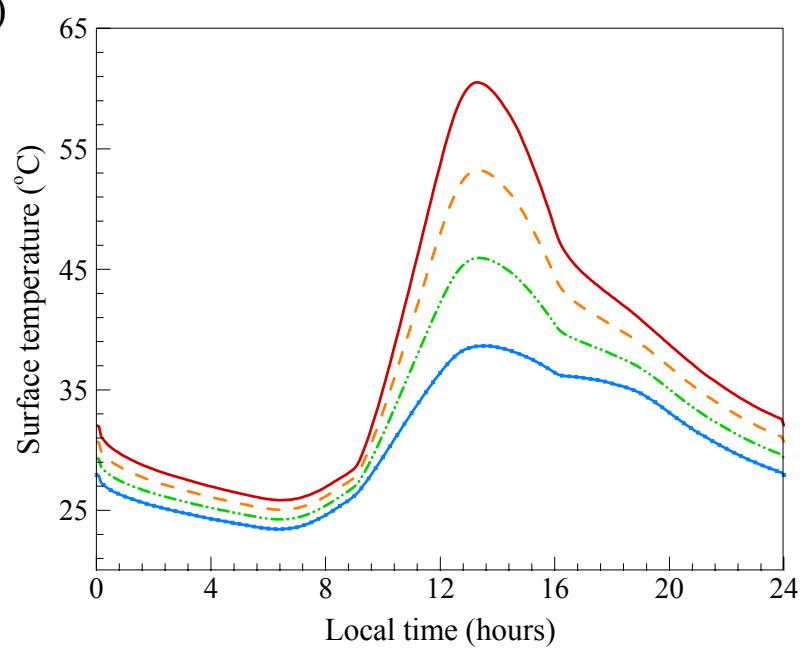

578 Figure 2. Averaged diurnal profiles of predicted pavement surface temperatures with different

579 albedo (a) without a canopy, and (b) in a high-density residential area in Phoenix during 12-17

$580 \quad$ June, 2012. 
(a)

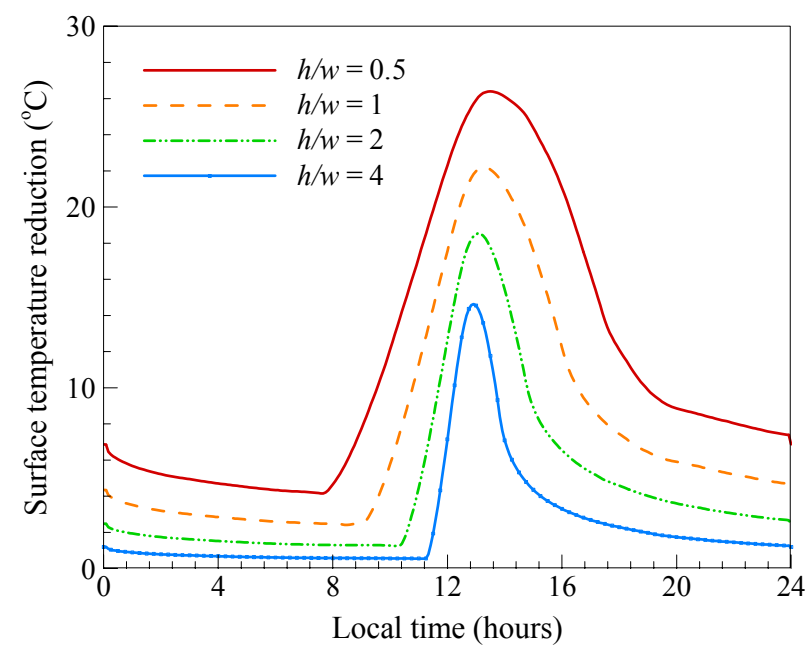

(b)

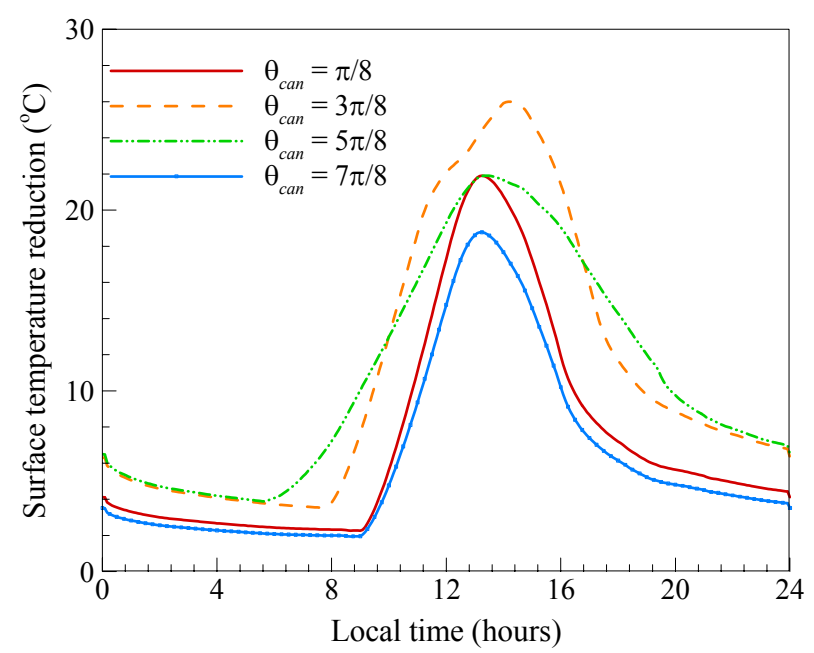

581 Figure 3. Averaged diurnal profiles of surface temperature reductions by increasing the 582 pavement albedo from 0.1 to 0.7 with different (a) aspect ratios $\left(\theta_{c a n}=\pi / 8\right)$, and (b) canyon 583 orientations $(h / w=1)$ in Phoenix during 12-17 June, 2012. 
(a)

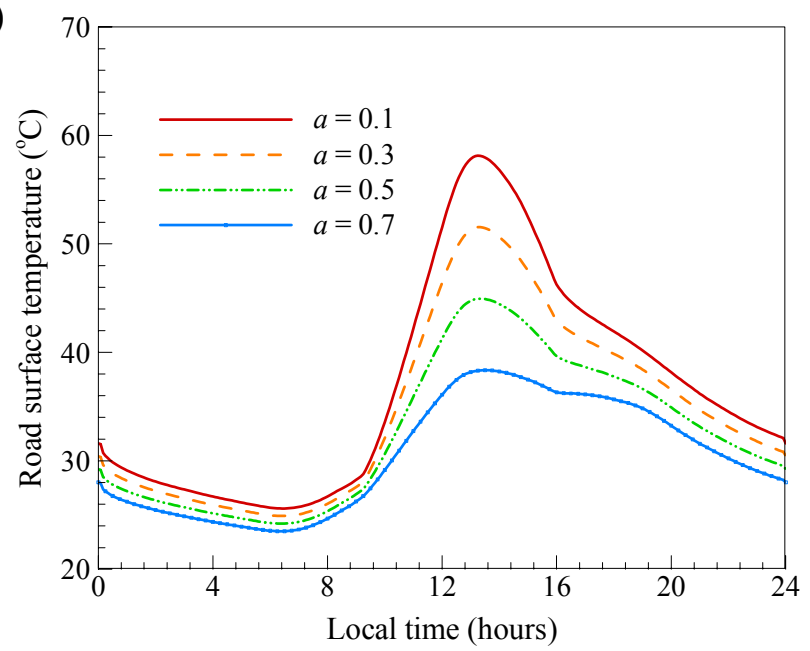

(b)

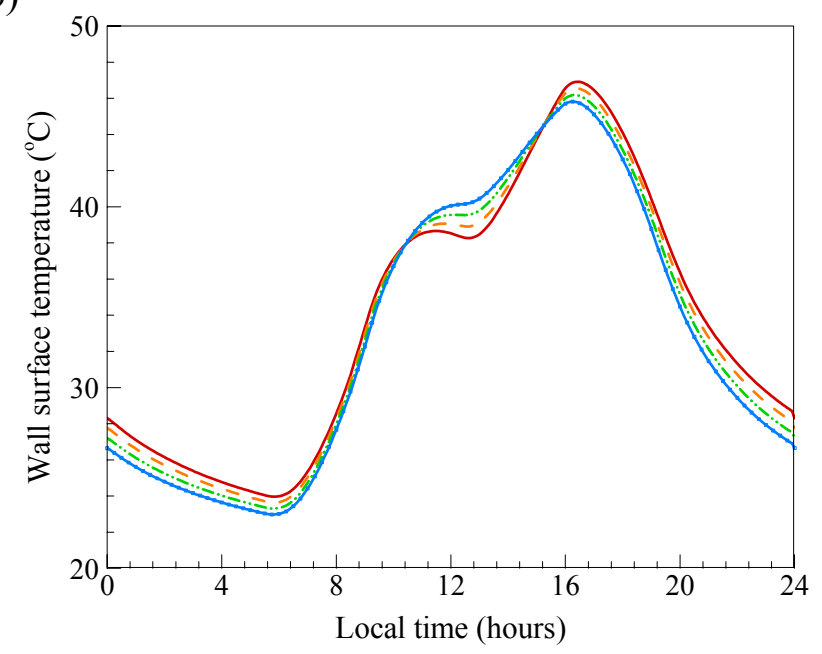

584 Figure 4. Simulated (a) road surface temperatures, and (b) wall surface temperatures with 585 different surface albedo for the pavement in Phoenix during 12-17 June, 2012. 
(a)

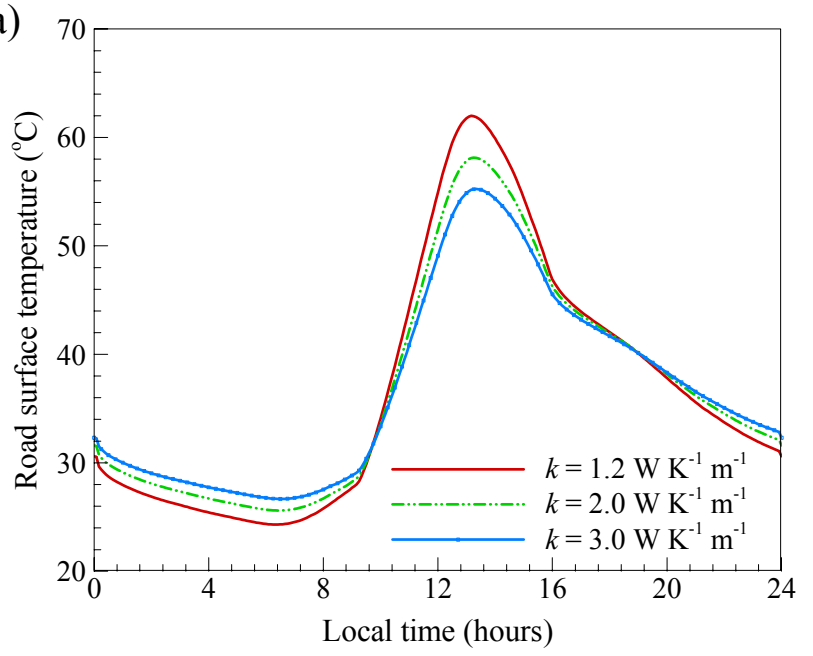

(b)

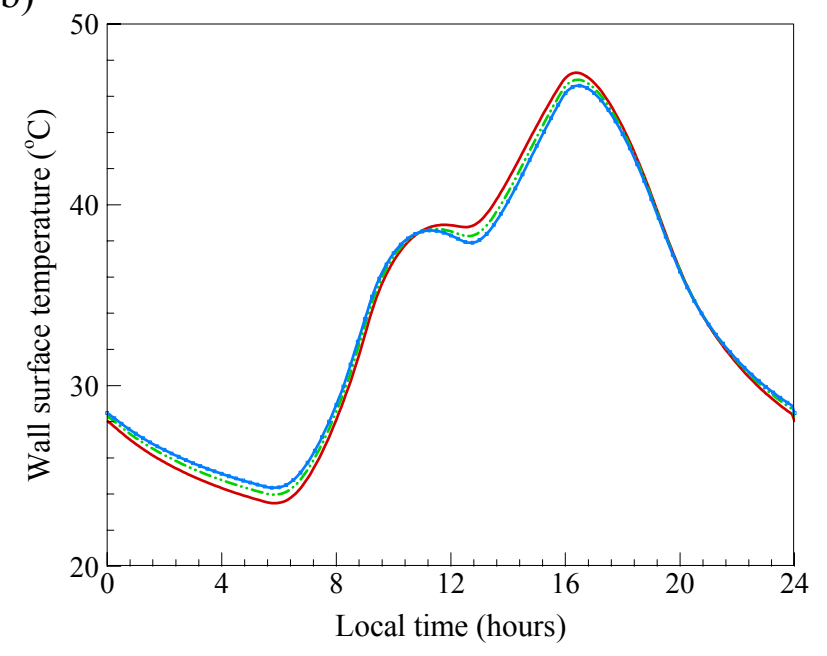

586 Figure 5. Simulated (a) road surface temperatures, and (b) wall surface temperatures with 587 different thermal conductivity for the pavement in Phoenix during 12-17 June, 2012. 
(a)

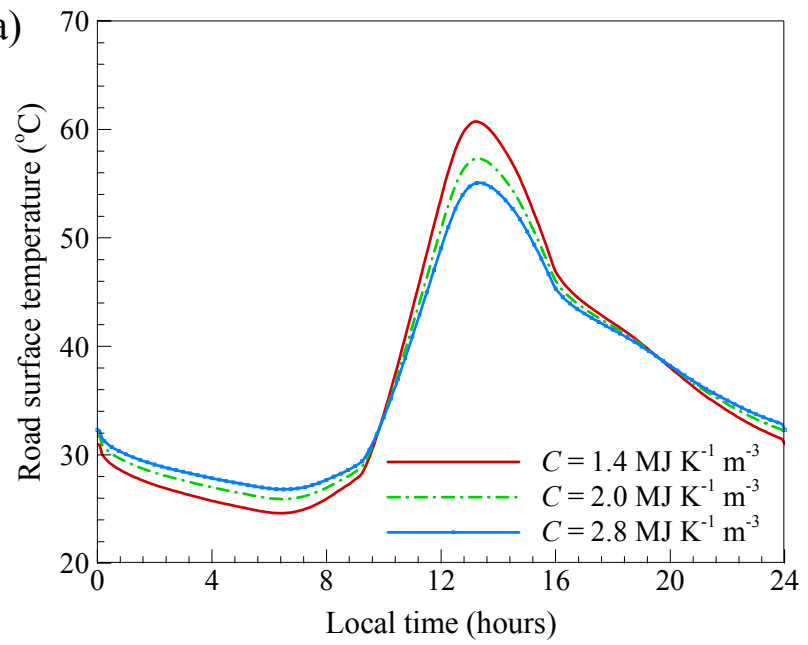

(b)

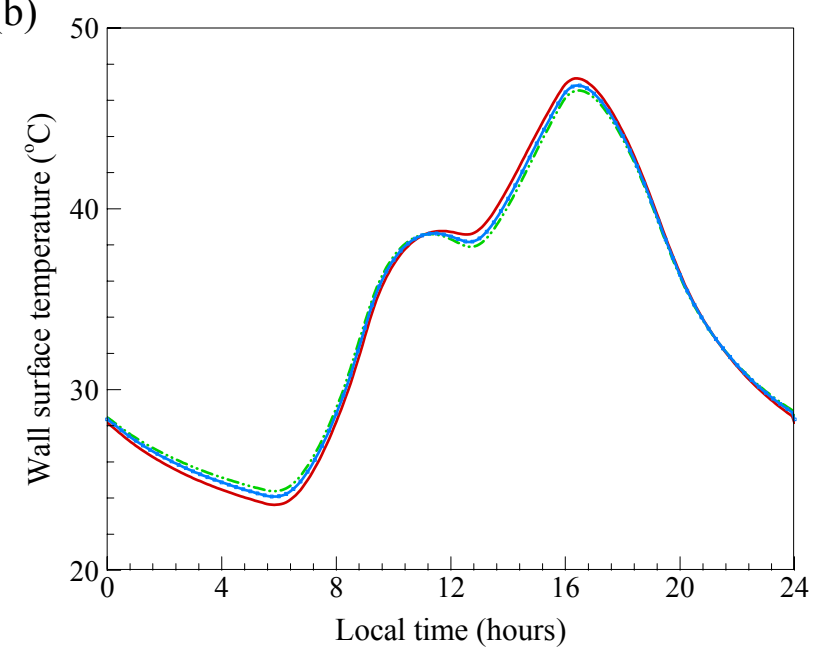

588 Figure 6. Simulated (a) road surface temperatures, and (b) wall surface temperatures with 589 different heat capacity for the pavement in Phoenix during 12-17 June, 2012. 
(a)

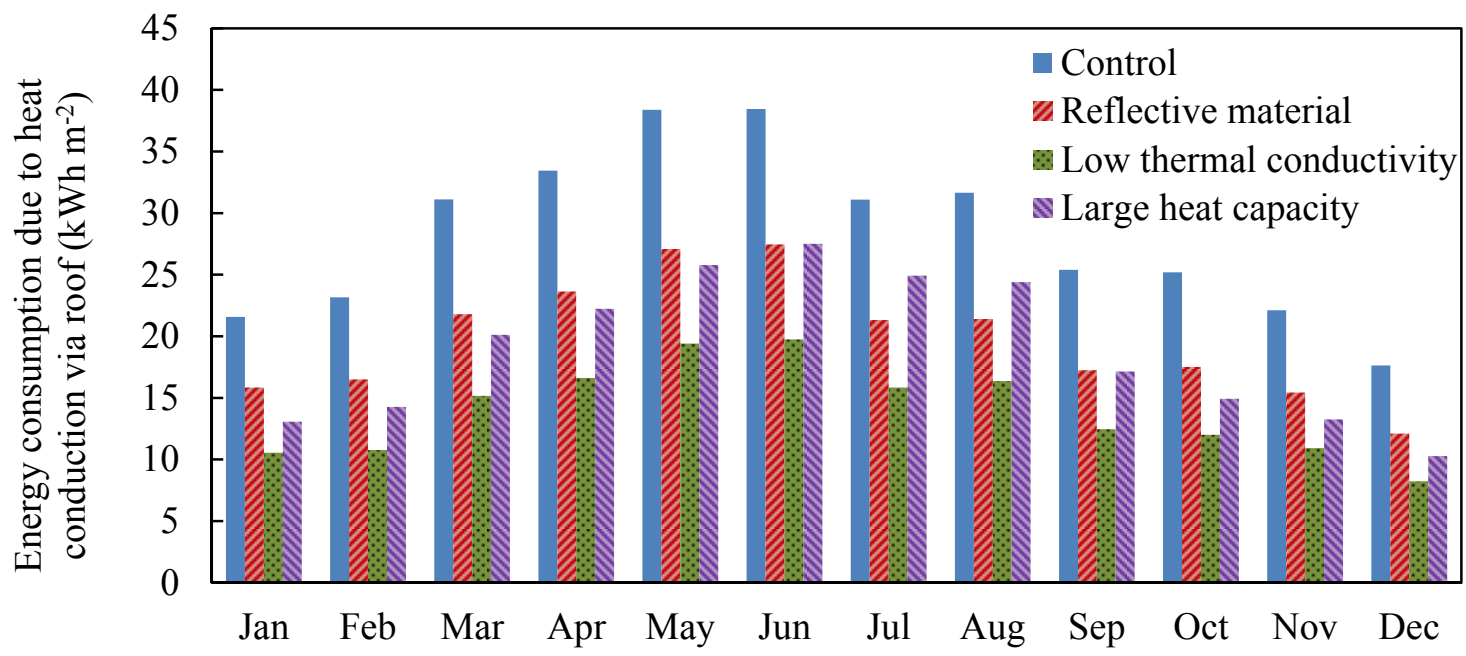

(b)

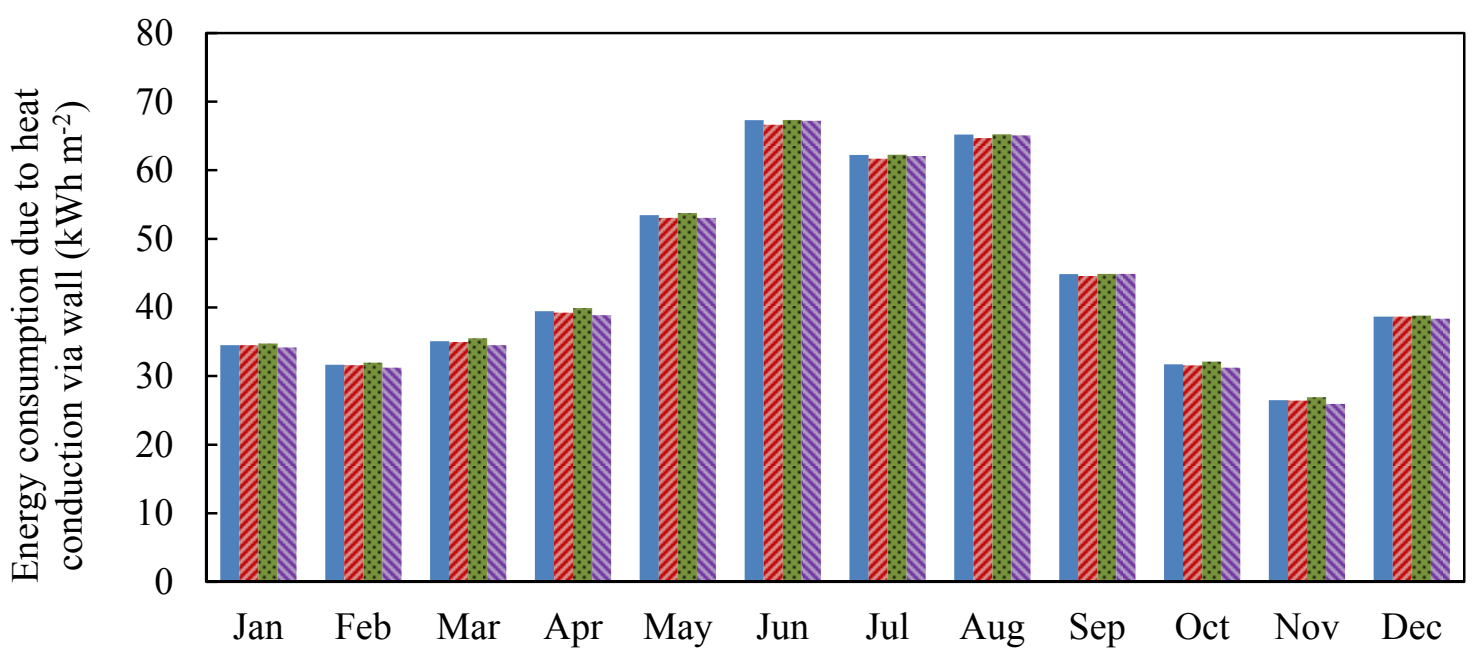

591

Figure 7. Monthly energy consumption of buildings due to heat conduction via (a) roof, and (b) wall with different engineering materials for Phoenix in 2012. 


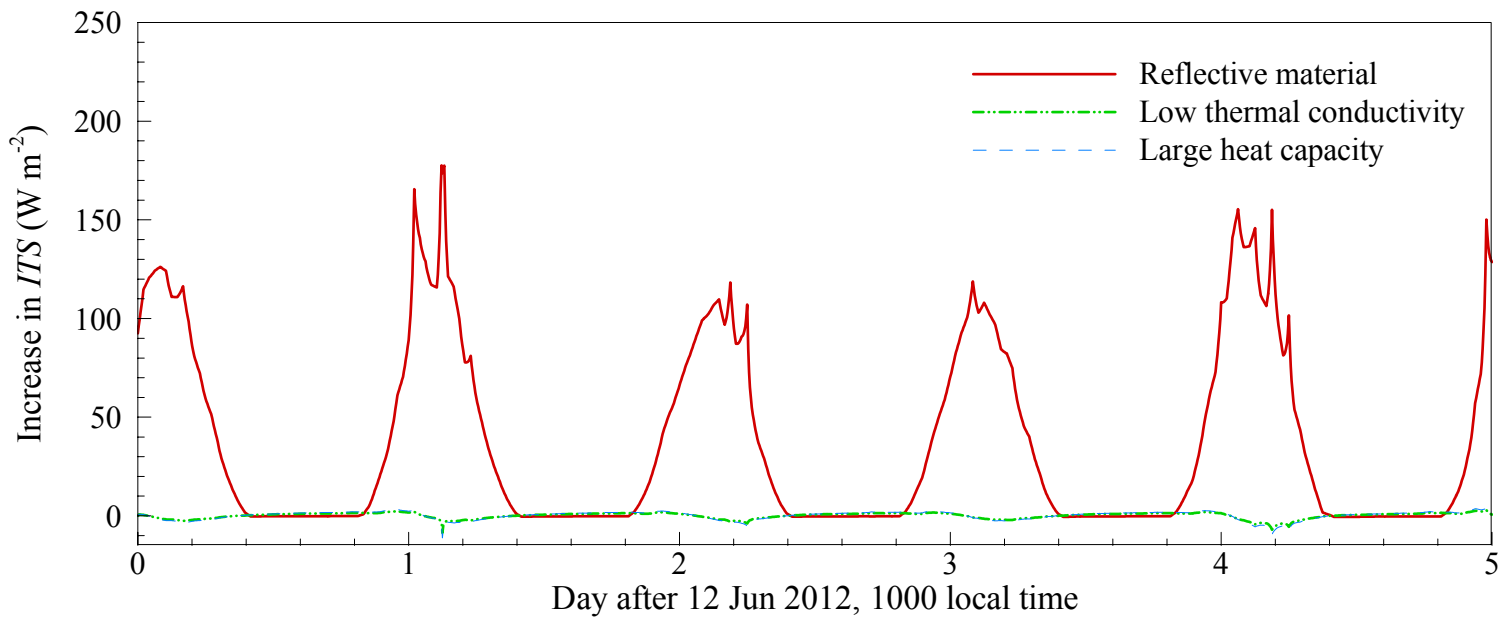

Figure 8. Increase in ITS of a pedestrian in the street canyon by different pavements during 12-

17 June, 2012 for Phoenix. 
(a)

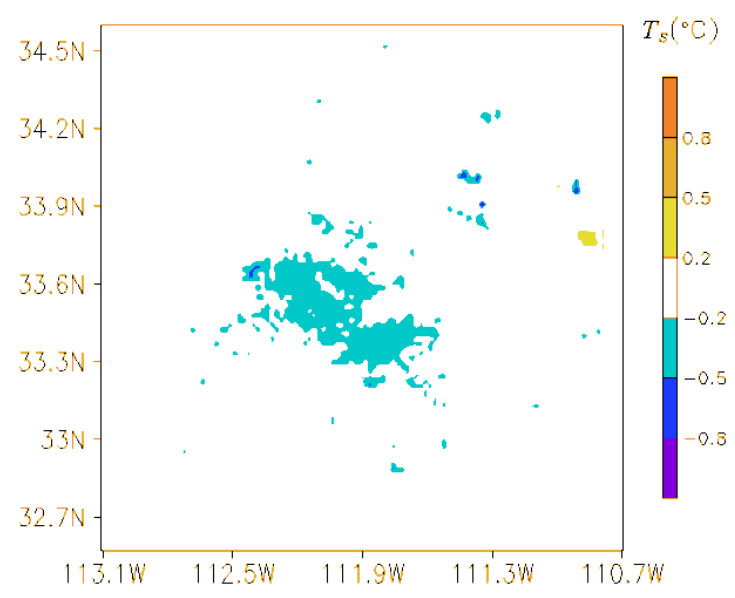

(b)

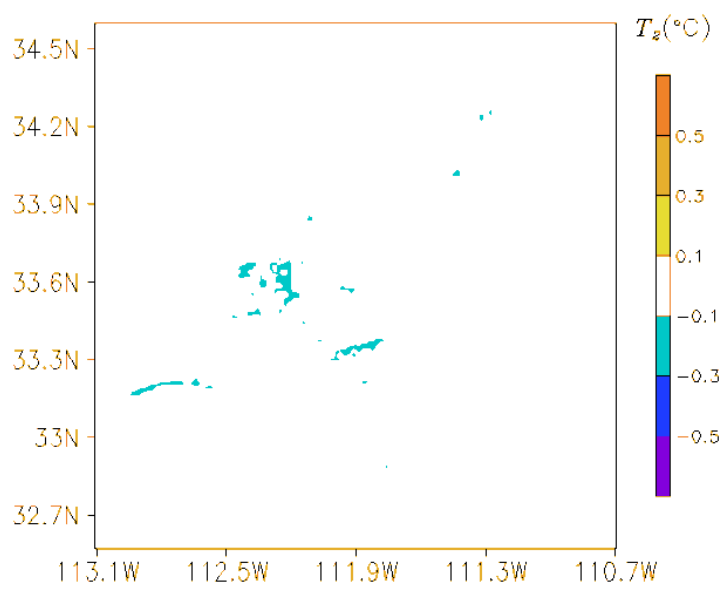

597 Figure 9. Simulated impact of the reflective pavement on (a) land surface temperature, and (b) 2598 m air temperature at 1400 local time for Phoenix. 
(a)

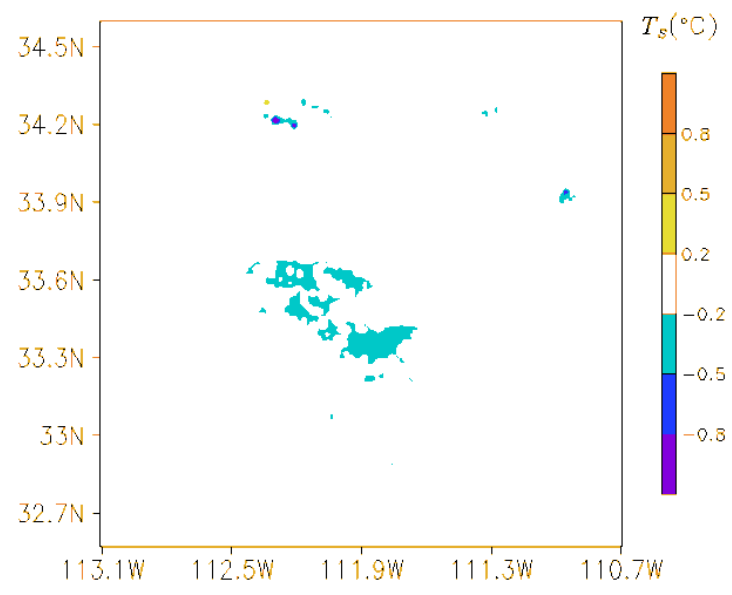

(b)

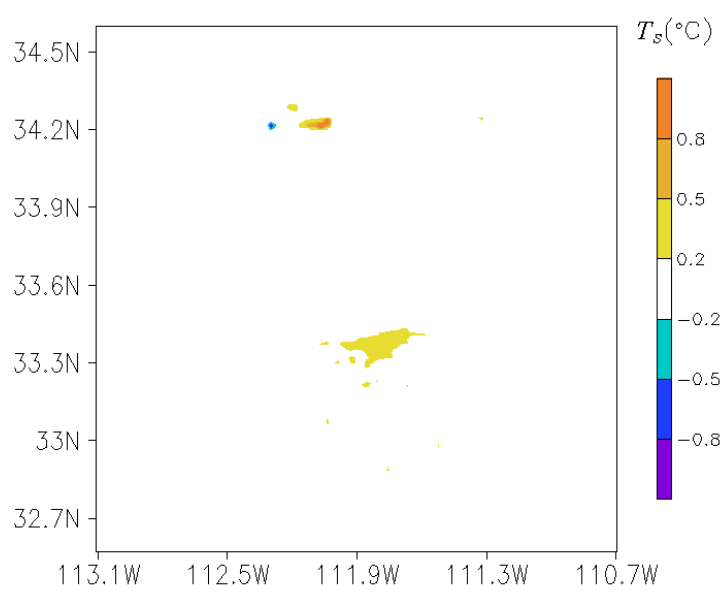

599 Figure 10. Simulated impact of (a) the pavement of large heat capacity and (b) the pavement of 600 low thermal conductivity on land surface temperature at 1400 local time for Phoenix. 


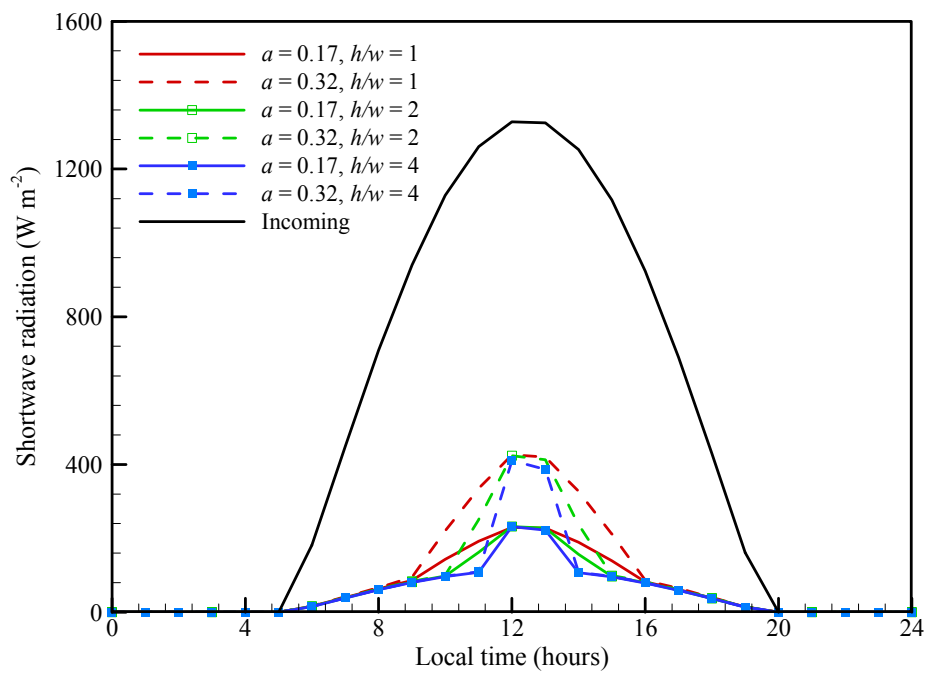

602 Figure 11. Diurnal profiles of incoming and reflected shortwave radiation for pavements with 603 different albedo in Phoenix urban canyon on the summer solstice day, 2012. 


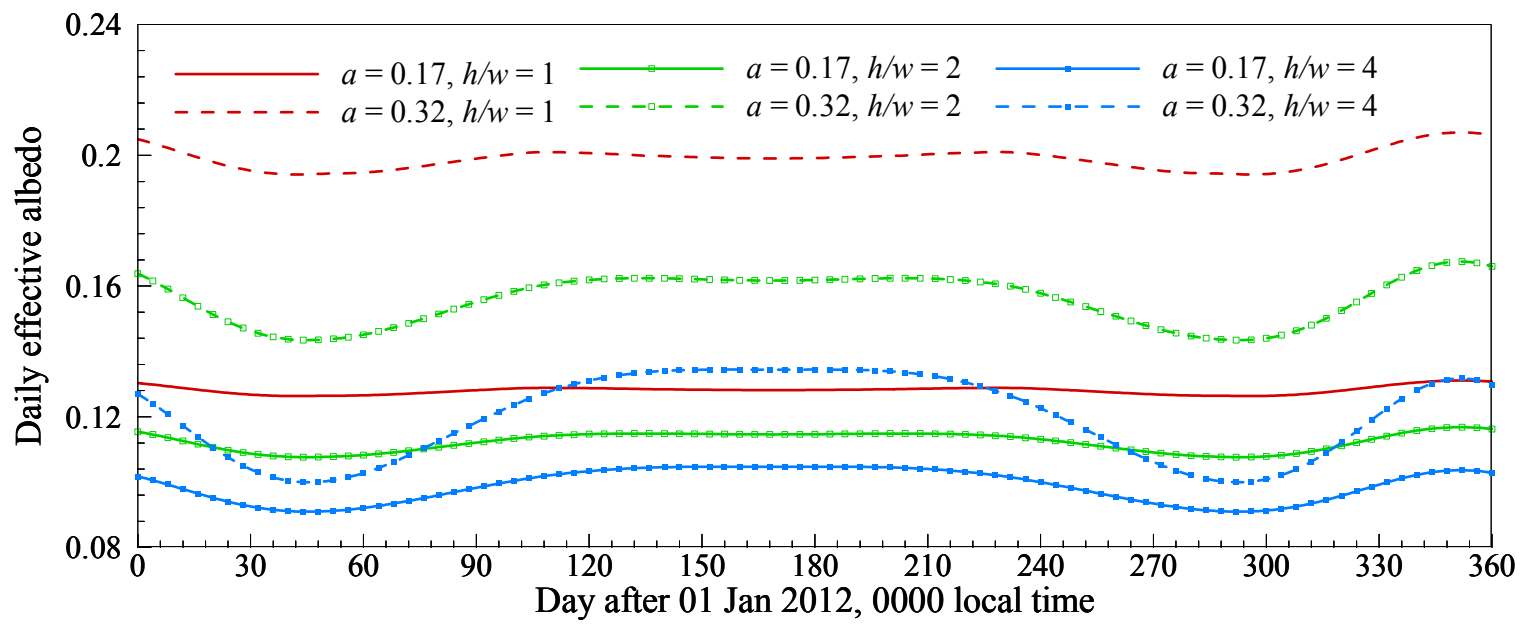

604

605 Figure 12. Seasonal variation of the daily effective albedo for pavements with material albedo of

$606 \quad 0.17$ and 0.32 in Phoenix urban canyon in year 2012. 
607 Table 1. Input parameters for a residential area in Phoenix using the urban canopy model.

\begin{tabular}{lcclcc}
\hline Input parameters & Symbol & Values & Input parameters & Symbol & Values \\
\hline Latitude (degree) & Lat & 34.42 & Normalized building height & $h$ & 0.5 \\
Longitude (degree) & Lon & 111.93 & Normalized canyon width & $w$ & 0.5 \\
Emissivity of ground (-) & $\varepsilon_{G}$ & 0.95 & Heat conductivity of ground $\left(\mathrm{W} \mathrm{m}^{-1} \mathrm{~K}^{-1}\right)$ & $k_{G}$ & 0.9 \\
Emissivity of wall (-) & $\varepsilon_{W}$ & 0.95 & Heat conductivity of wall $\left(\mathrm{W} \mathrm{m}^{-1} \mathrm{~K}^{-1}\right)$ & $k_{W}$ & 1.3 \\
Emissivity of roof (-) & $\varepsilon_{R}$ & 0.95 & Heat conductivity of roof $\left(\mathrm{W} \mathrm{m}^{-1} \mathrm{~K}^{-1}\right)$ & $k_{R}$ & 1.2 \\
Albedo of ground (-) & $a_{G}$ & 0.1 & Heat capacity of ground $\left(\mathrm{MJ} \mathrm{m}^{-3} \mathrm{~K}^{-1}\right)$ & $C_{G}$ & 2.1 \\
Albedo of wall (-) & $a_{W}$ & 0.2 & Heat capacity of wall $\left(\mathrm{MJ} \mathrm{m}^{-3} \mathrm{~K}^{-1}\right)$ & $C_{W}$ & 1.5 \\
Albedo of roof (-) & $a_{R}$ & 0.1 & Heat capacity of roof $\left(\mathrm{MJ} \mathrm{m}^{-3} \mathrm{~K}^{-1}\right)$ & $C_{R}$ & 1.9 \\
Thickness of wall (m) & $d_{W}$ & 0.18 & Roughness length above roof $(\mathrm{m})$ & $Z_{m, R}$ & 0.01 \\
Thickness of roof (m) & $d_{R}$ & 0.3 & Roughness length above ground $(\mathrm{m})$ & $Z_{m, G}$ & 0.05 \\
Canyon orientation & $\theta_{c a n}$ & $\pi / 8$ & & & \\
\hline
\end{tabular}


609 Table 2. Summary of thermal properties and total annual energy consumptions in different

610 simulation cases for Phoenix in 2012.

\begin{tabular}{|c|c|c|c|c|}
\hline & Control case & $\begin{array}{c}\text { Reflective } \\
\text { material }\end{array}$ & $\begin{array}{c}\text { Material of low } \\
\text { thermal conductivity }\end{array}$ & $\begin{array}{c}\text { Material of large } \\
\text { heat capacity }\end{array}$ \\
\hline Albedo & 0.1 & 0.5 & 0.1 & 0.1 \\
\hline $\begin{array}{l}\text { Thermal conductivity } \\
\left(\mathrm{W} \mathrm{K}^{-1} \mathrm{~m}^{-1}\right)\end{array}$ & 1.2 & 1.2 & 0.6 & 1.2 \\
\hline Heat capacity $\left(\mathrm{MJ} \mathrm{K}^{-1} \mathrm{~m}^{-3}\right)$ & 1.4 & 1.4 & 1.4 & 2.8 \\
\hline $\begin{array}{l}\text { Total annual energy } \\
\text { consumption through roof } \\
\left(\mathrm{kWh} \mathrm{m}^{-2}\right)\end{array}$ & 339 & 238 & 168 & 228 \\
\hline $\begin{array}{l}\text { Total annual energy } \\
\text { consumption through wall } \\
\left(\mathrm{kWh} \mathrm{m}^{-2}\right)\end{array}$ & 727 & 707 & 734 & 719 \\
\hline
\end{tabular}

611 
612 Table 3. Summary of input parameters for different urban-land categories in the WRF-Urban

613 modeling system for metropolitan Phoenix.

\begin{tabular}{llccc}
\hline Input parameters & Unit & $\begin{array}{c}\text { Industrial and } \\
\text { commercial }\end{array}$ & $\begin{array}{c}\text { High-density } \\
\text { residential }\end{array}$ & $\begin{array}{c}\text { Low-density } \\
\text { residential }\end{array}$ \\
\hline$h$ (building height) & $\mathrm{m}$ & 17.0 & 7.5 & 5.0 \\
$l_{\text {roof }}$ (roof width) & $\mathrm{m}$ & 10.0 & 9.4 & 8.3 \\
$l_{\text {road }}$ (road width) & $\mathrm{m}$ & 10.0 & 9.4 & 8.3 \\
$f_{\text {urb }}$ (urban fraction) & - & 0.95 & 0.85 & 0.65 \\
$a_{R}$ (albedo of roof) & - & 0.15 & 0.16 & 0.16 \\
$a_{W}$ (albedo of wall) & - & 0.15 & 0.16 & 0.16 \\
$a_{G}$ (albedo of ground) & - & 0.17 & 0.17 & 0.17 \\
$C_{R}$ (heat capacity of roof) & $\mathrm{MJ} \mathrm{K}^{-1} \mathrm{~m}^{-3}$ & 1.35 & 1.35 & 1.35 \\
$C_{W}$ (heat capacity of wall) & $\mathrm{MJ} \mathrm{K}^{-1} \mathrm{~m}^{-3}$ & 1.35 & 1.35 & 1.35 \\
$C_{G}$ (heat capacity of ground) & $\mathrm{MJ} \mathrm{K}^{-1} \mathrm{~m}^{-3}$ & 1.4 & 1.4 & 1.4 \\
$k_{R}$ (thermal conductivity of roof) & $\mathrm{W} \mathrm{K}^{-1} \mathrm{~m}^{-1}$ & 0.70 & 0.70 & 0.70 \\
$k_{W}$ (thermal conductivity of wall) & $\mathrm{W} \mathrm{K}^{-1} \mathrm{~m}^{-1}$ & 0.70 & 0.70 & 0.70 \\
$k_{G}$ (thermal conductivity of ground) & $\mathrm{W} \mathrm{K}^{-1} \mathrm{~m}^{-1}$ & 1.2 & 1.2 & 1.2 \\
\hline
\end{tabular}

